\title{
End Stage Renal Disease and Renal Replacement Therapy - Challenges and Future Prospective in Nepal
}

\author{
Hada $R^{1}$ \\ 'Nephrology Unit, National Academy of Medical Sciences, Bir hospital, Kathmandu, Nepal.
}

\section{INTRODUCTION}

Only renal replacement therapy (RRT) either maintenance dialysis or kidney transplantation can save the life of end stage renal disease (ESRD) patients. Almost all ESRD patients in developed countries receive one or other form of RRT and get the opportunity to survive longer due to availability of government support and health insurance policy. The scenario is entirely different in developing world. Due to ignorance, illiteracy and poverty majority never see nephrologists and die at home. Among those who seek RRT, most reach hospital in critical state needing urgent dialysis with increased risk of morbidity and mortality. Due to unaffordability, lack of government support and health insurance, only few ESRD patients can continue maintenance haemodialysis (HD) for more than three months. ${ }^{1}$

History of nephrology service in Nepal evolves from management of all sorts of kidney disease patients with initiation of intermittent peritoneal dialysis (IPD) and

kidney biopsy in 1973, establishment of HD service in 1987 to successful kidney transplantation in $2008 .^{2,3}$ With the rapidly increasing population and kidney disease patients, the service in the country is still insufficient with inadequate human resources in the field.
Incidence of ESRD

The incidence of ESRD population is increasing all over the world. Due to lack of ESRD registry the exact incidence of ESRD in developing countries is not known.

In Nepal, total 1393 (data compiled from all four dialysis centers) ESRD patients received RRT from 1990-1999. The prevalence showed increasing trend from 61 patients per year in 1990 to 270 patients per year in 1999 with six per million populations on RRT in the decade. ${ }^{4}$

After 2000, the total RRT patients in all dialysis centers of Nepal is not yet compiled and reported. However, a single center study in Bir hospital in five years period has shown dramatically increasing incidence of 102 in $2001 / 2002$ to 178 in 2005/2006 with an average of 160 new ESRD patients enrollment per year. ${ }^{5}$

It has been estimated that the incidence of new ESRD in South Asian countries India, Bangladesh and Pakistan is around 100 per million populations (pmp) per year and $10 \%$ of estimated ESRD ever seek RRT. ${ }^{1,6,7}$ From 19901999 , only $0.3 \%$ of estimated ESRD received $R R T$ in Nepal. ${ }^{4}$ With increasing population, the estimated ESRD in Nepal will also increase. The projected population and estimated new ESRD in all development regions of Nepal in 2011, 2016 and 2021 indicates the increasing burden of disease all over the country (Table 1).
Correspondence:
Dr. Rajani Hada
Nephrology Unit
National Academy of Medical Sciences
Bir Hospital, Kathmandu, Nepal.
Email: rajani.hada@hotmail.com
Phone: 977-9841226688

\section{JNMA | VaL 48 Na.4 | ISSUE 176 口CT-DEC, 2009}


Table 1. Projected population of Nepal and estimated ESRD in development regions of Nepal in 2011, 2016 and 2021

\begin{tabular}{|c|c|c|c|c|c|c|}
\hline \multirow{3}{*}{$\begin{array}{l}\text { Regions } \\
\text { of Nepal }\end{array}$} & \multicolumn{2}{|c|}{2011} & \multicolumn{2}{|c|}{2016} & \multicolumn{2}{|c|}{2021} \\
\hline & Population & Estimated & Population & Estimated & Population & Estimated \\
\hline & in million ${ }^{a}$ & $\mathrm{ESRD}^{\mathrm{b}}$ & in million ${ }^{a}$ & $\mathrm{ESRD}^{\mathrm{b}}$ & in million ${ }^{a}$ & $\mathrm{ESRD}^{\mathrm{b}}$ \\
\hline Eastern & 6.48 & 648 & 7.06 & 706 & 7.67 & 767 \\
\hline Central & 10.06 & 1006 & 11.08 & 1108 & 12.13 & 1213 \\
\hline Western & 5.56 & 556 & 6.07 & 607 & 6.60 & 660 \\
\hline Mid Western & 3.71 & 371 & 4.07 & 407 & 4.43 & 443 \\
\hline Far Western & 2.75 & 275 & 3.03 & 303 & 3.32 & 332 \\
\hline Total & 28.56 & 2856 & 31.31 & 3131 & 34.15 & 3415 \\
\hline
\end{tabular}

a Population Projection by age and sex of Development Regions (Median variant). Population projections for Nepal, 2001 - 2021, Central Bureau of Statistics, 2003;Dec. 32-41.

${ }^{\mathrm{b}}$ Estimated incidence of new ESRD with 100 per million population per year as par with South Asian countries ${ }^{1,6,7}$

\section{Demography of ESRD}

ESRD had shown male preponderance with mean age of 46 years and $66-70 \%$ of ESRD patients in the age range of 20-60 years reveal the great loss of human resources in the country without treatment. ${ }^{4,5}$

The three leading cause of ESRD in Nepal were chronic glomerulonephritis (CGN) (40.6\%), diabetic nephropathy $(16.8 \%)$ and hypertensive nephrosclerosis $(13.7 \%)$ and CGN was the commonest cause (36\%) of ESRD below 60 years. ${ }^{5}$ Cause could not be ascertained in 13-18\% as they report at the terminal stage with bilateral contracted kidneys.

\section{Intermittent Peritoneal Dialysis}

IPD is an obsolete mode of RRT for ESRD in developed world. IPD is a simple procedure that can be started easily and without delay as a life saving emergency dialysis in all district hospitals of Nepal. ${ }^{9}$ But it is still practiced even in tertiary hospital of Nepal and $60 \%$ of ESRD were found to receive only IPD and die within three months as they could not afford for costly maintenance HD and transplantation. ${ }^{4,5}$

\section{Haemodialysis}

HD was started in Bir hospital in 1987 and expanded to three other centers in Kathmandu by 1997 with total 15 HD machines. Gradually the HD facility has increased outside and inside capital in post graduate institutes, private hospitals and medical colleges. In 2008, government took a progressive step to initiate HD in at least one government hospitals outside Kathmandu and provided necessary equipments. By December 2009, there were total 22 hospitals with $121 \mathrm{HD}$ machines in the country (Table 2). The dialysis centers have increased dramatically after 2006 particularly due to provision of facility in medical colleges (Figure 1). The HD center is available in five zones and four regions of the country with 11 centers inside the Kathmandu valley (Figure 2). Seven centers including four government hospitals with newly established HD facility have not started HD yet. 
Hada et al. End Stage Renal Disease and Renal Replacement Therapy - Challenges and Future Prospective in Nepal

Table 2. Haemodialysis centers in Nepal from 1987 - 2009.

\begin{tabular}{|c|c|c|c|c|c|c|c|}
\hline SN & Hospital & Zone & $\begin{array}{l}\text { Location } \\
\text { District }\end{array}$ & Region & $\begin{array}{c}\text { Established } \\
\text { Year }\end{array}$ & $\begin{array}{l}\text { HD Machine } \\
\text { number }\end{array}$ & $\begin{array}{l}\text { Type of } \\
\text { Hospital }\end{array}$ \\
\hline 1 & Bir Hospital & Bagmati & Kathmandu & Central & 1987 & 10 & Government \\
\hline 2 & Shree Birendra Hospital & Bagmati & Kathmandu & Central & 1995 & 3 & Army \\
\hline 3 & TUTH & Bagmati & Kathmandu & Central & 1996 & 9 & Post graduate \\
\hline 4 & National Kidney Centre & Bagmati & Kathmandu & Central & 1997 & 32 & NGO \\
\hline 5 & BPKIHS & Koshi & Dharan & Eastern & 1999 & 10 & Post graduate \\
\hline 6 & B \& B hospital & Bagmati & Kathmandu & Central & 2000 & 4 & Private \\
\hline 7 & Blue Cross Nursing Home & Bagmati & Kathmandu & Central & 2000 & 5 & Private \\
\hline 8 & Nepal Medical College & Bagmati & Kathmandu & Central & 2003 & 6 & Medical college \\
\hline 9 & Life Care Hospital & Bagmati & Kathmandu & Central & 2006 & 4 & Private \\
\hline 10 & Nepalgunj Medical College & Bheri & Nepalganj & Mid western & 2007 & 2 & Medical college \\
\hline 11 & National Medical College & Narayani & Birgunj & Central & 2007 & 2 & Medical college \\
\hline 12 & Bharatpur Medical College & Narayani & Bharatpur & Central & 2007 & 4 & Medical college \\
\hline 13 & Manipal Medical College & Gandaki & Pokhara & Western & 2008 & 3 & Medical college \\
\hline 14 & Birendra Police Hospital* & Bagmati & Kathmandu & Central & 2008 & 5 & Police \\
\hline 15 & Koshi Zonal Hospital* & Koshi & Biratnagar & Eastern & 2008 & 2 & Government \\
\hline 16 & Western Regional Hospital ${ }^{*}$ & Gandaki & Pokhara & Western & 2009 & 2 & Government \\
\hline 17 & Kantipur Hospital* & Bagmati & Kathmandu & Central & 2009 & 2 & Private \\
\hline 18 & Patan Hospital* & Bagmati & Lalitpur & Central & 2009 & 5 & Public \\
\hline 19 & Bheri Zonal hospital* & Bheri & Nepalganj & Mid Western & 2009 & 4 & Government \\
\hline 20 & Narayani Zonal hospital* & Narayani & Birgunj & Central & 2009 & 2 & Government \\
\hline 21 & Gandaki Medical College & Gandaki & Pokhara & Western & 2009 & 2 & Medical college \\
\hline 22 & Kist Medical College & Bagmati & Kathmandu & Central & 2009 & 5 & Medical college \\
\hline
\end{tabular}

${ }^{*}$ Centers with dialysis facility not yet in operation by the end of December 2009. 


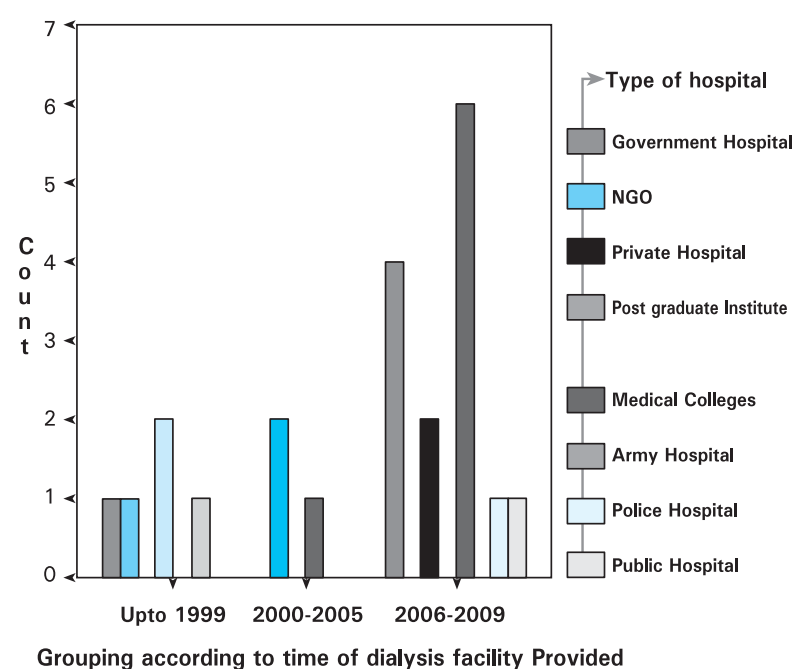

Figure 1. Haemodialysis centers in different types of hospitals of Nepal till 2009.

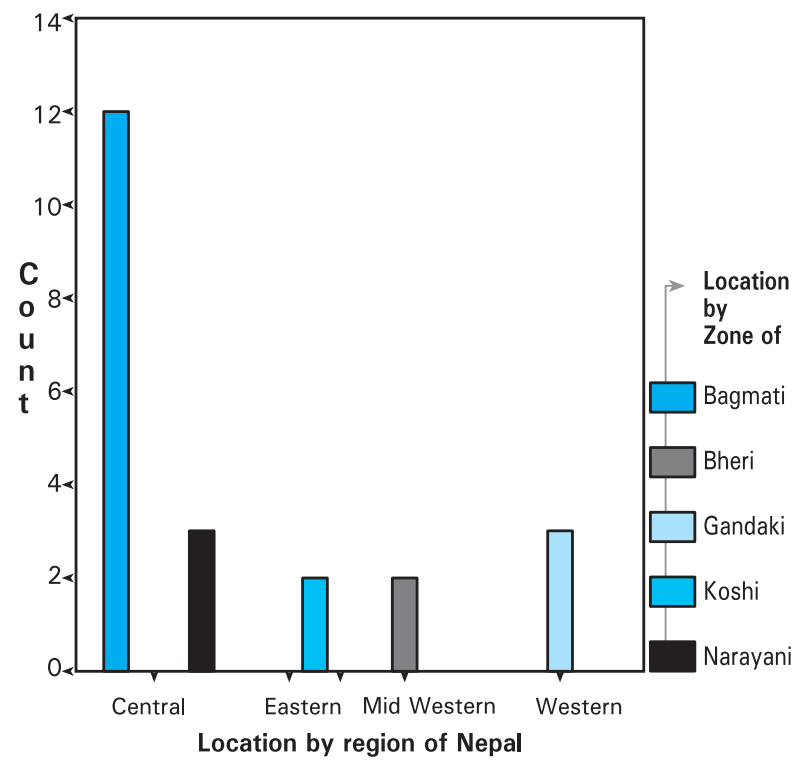

Figure 2. Haemodialysis centers in different regions and zones of Nepal till 2009.

Patient survival in maintenance HD depends upon multiple factors like timely initiation of dialysis, adequacy of dialysis, co-morbid conditions, infection, malnutrition etc. Studies had shown the survival of only $8.7 \%$ 13.3\% ESRD on maintenance HD for more than three months and $5.4 \%$ ESRD on maintenance HD for more than one year in Nepal. That could be due to poor physical health, inadequate dialysis, anemia, hypertension, hyperphosphatemia etc though the factors affecting mortality and morbidity on MHD is not studied elaborately yet. $^{4,5,10-12}$

\section{Kidney Transplantation}

Kidney transplantation is the best and cheap RRT for ESRD. But due to low socioeconomic condition only $3.8 \%-9.5 \%$ could afford kidney transplantation. ${ }^{4,5}$ Until 2008, almost all transplant recipients had undergone kidney transplantation in India with $70 \%$ receiving kidney from unrelated donor and $60 \%$ of recipients in the age group of 16-45 years. ${ }^{13}$ Kidney transplantation was legalized in Nepal in 2000. ${ }^{14}$ But successful kidney transplantation could be performed in Nepal only on $8^{\text {th }}$ August 2008 in TUTH $^{3}$ and on $12^{\text {th }}$ December 2008 in Bir hospital. ${ }^{15}$ By the end of 2009 , total 63 recipients (TUTH - 45 and Bir hospital - 18) have undergone live legally related kidney transplantation in Nepal. The HLA typing and cross match that is mandatory for kidney transplantation and the drug monitoring facility after transplantation is not available in the country and it is done by sending the blood samples to India. ${ }^{15}$

\section{Cost of RRT}

RRT is a costly treatment all over the world and it is rarely the government priority in developing countries. The cost analysis study of RRT in Nepal is not yet published. Besides drugs and transportation, the present annual cost for twice weekly MHD per patient is approximately US \$2000 (NRS 12500) in government hospital and US\$ 4000 (NRS 25000) (US \$ $1=$ NRS $75)$ in private and non government sectors. The cost of kidney transplantation operation in Bir hospital is US \$ 4600 (NRS 350,000) that includes the total hospital cost and immunosuppressive therapy including induction therapy for two weeks and the estimated annual cost of immunosuppressive therapy thereafter is around US\$ 3200 (NRS 20000 per month) though it varies from person to person. ${ }^{15}$

\section{Human resources in Nephrology}

Until 1999, there were total nine doctors (nephrologists and internists) involved in nephrology service in the country. ${ }^{4}$ After a decade, though the service has expanded in many centers located in different parts of the country, the human resources in the field has not increased significantly. Nepal has total 14 nephrologists and 10 physicians giving nephrology care at present. Among 14 nephrologists, there are only two government nephrologists, both working at Bir Hospital and only two nephrologists working outside capital.

\section{Future Recommendations}

Incidence of ESRD is increasing with increasing population even in Nepal, affecting mostly the younger age group. 
Nephrologists in the country are very few in number to serve increasing number of ESRD patients. The treatment is very costly and majority die within thre months. Dialysis facility is inadequate and centralized and inaccessible to poor patients from remote areas. Therefore, in order to prevent ESRD and expand the nephrology services in different parts of the country following facts have to be addressed by different authorities.

1. Post graduate courses in Nephrology: Without increasing nephrologists in the country, merely expanding dialysis facility will not provide quality care and prevention of ESRD. So, NAMS, TUTH and BPKIHS should start MD/DM nephrology course as soon as possible.

2. Public and non government organizations: The organizations interested to invest in health sector should realize the utmost need of institute on nephrology, urology and transplantation in the country and come forward for the same all alone or in collaboration with other institutions.

3. Nepal government: Nepal being the developing country with low per capita income, Ministry of Health and Population should take the lead both in preventive and therapeutic interventions on ESRD as follows -

a) Development of short term plan to provide scholarship and attract for MD/DM course in nephrology b) Development of five years and 10 years proposal on establishment of dialysis facility in Regional and Zonal level

c) Establishment of independent national institute of nephrology, urology and transplantation (NUT) or play the role of catalyst to establish public institute on NUT.

d) Developing software to start registry on ESRD and other kidney diseases.

e) Working with Education Ministry and implement following preventive measures i) Screening of school going children by simpler and cheaper urine analysis (NRS 15 to 25 in government and 50 to 60 in private hospital) on school admission with further investigation if necessary and then at least once in every five years. ii) Including preliminary knowledge of kidney disease, hypertension and diabetes in the school syllabus.

f) Taking necessary steps to reduce tax on immunosuppressive drugs and establishment of HLA and drug monitoring laboratory in the country for reduction of cost for kidney transplantation.

\section{REFERENCES}

1. Kher V. End-stage renal disease in developing countries. Kidney Int. 2002;62:350-62.

2. Hada R. Kidney transplantation in Nepal. Postgraduate Medical Journal of Nepal. 2003;4:51-4.

3. Kafle RK. Current trends of transplantation in Nepal. Journal Nephrology and Renal Transplantation (JNRT). 2009;2(1):89-93.

4. Hada R, Khakurel S, Agrawal RK, Kafle RK, Bajracharya SB, Raut KB. Incidence of end stage renal disease on renal replacement therapy in Nepal. Kathmandu Univ Med J (KUMJ). 2009;7(3):301-5.

5. Khakurel S, Agrawal RK, Hada R. Pattern of end stage renal disease in a tertiary care center. J Nepal Med Assoc. 2009;48(2):126-30.

6. Naqvi SAJ. Nephrology services in Pakistan. Nephrol Dial Transpl. 2000;15:769-71.

7. Rashid HU. Health delivery system for renal disease care in Bangladesh. Saudi J kidney Dis Transpl. 2004;15:185-9.

8. Chhetri PK, Manadhar DN, Bhattarai SP, Pahari LR, Shrestha R. Chronic kidney disease 5 on haemodialysis in Nepal Medical College Teaching Hospital. Nepal Med Coll J. 2008;10(1):8-10.

9. Sharma SK, Manadhar D, Singh J, Chauhan HS, Koirala B, Gautam M, et al. Acute peritoneal dialysis in eastern Nepal. Perit Dial Int. 2003;23:Suppl(2)S196-S199.
10. Shrestha S, Ghotekar LR, Sharma SK, Shangwa PM, Karki P. Assessment of quality of life in patients of end stage renal disease on different modalities of treatment. J Nepal Med Assoc. 2008;47(169):1-6.

11. Manandhar DN, Chhetri PK, Tiwari R, Lamichhane S. Evaluation of dialysis adequacy in patients under haemodialysis and effectiveness of dialyser reuses. Nepal Med Coll J. 2009;11(2):107-10.

12. Hada R, Khakurel S, Agrawal RK. Intact parathyroid hormone, calcium, phosphate and radiological changes in maintenance haemodialysis and newly diagnosed end stage renal disease patients. Bang Renal J. 2005;24(1):5-11.

13. Dulal RK, Karki S. Nepalese kidney transplant recipient in a follow up clinic: related and unrelated living donor. J Nepal Med Assoc. 2008;47(171):98-103.

14. Kidney Transplantation Act 2058 (B.S.) in Compilation of 8. Health Act and Regulations. $5^{\text {th }}$ ed. Reprint in Fagun 2064:277293. Kathmandu: Makalu Publication; 2006. p. 277-93.

15. Kidney Transplant: a success story at Bir Hospital. The Rising Nepal. 2009 Dec 13;XLIV(351):1(col.2).

\section{JNMA VםL 48}

